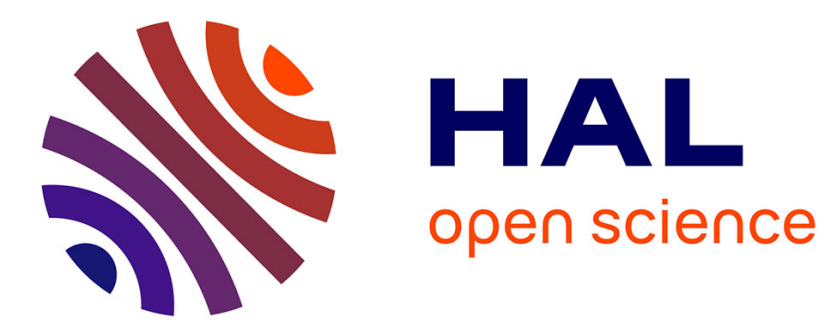

\title{
Combustion modeling in large scale volumes using EUROPLEXUS code
}

\author{
A. Velikorodny, E. Studer, S. Kudriakov, A. Beccantini
}

\section{To cite this version:}

A. Velikorodny, E. Studer, S. Kudriakov, A. Beccantini. Combustion modeling in large scale volumes using EUROPLEXUS code. Journal of Loss Prevention in the Process Industries, 2015, 35, pp.104-116. 10.1016/j.jlp.2015.03.014 . cea-02506800

\section{HAL Id: cea-02506800 https://hal-cea.archives-ouvertes.fr/cea-02506800}

Submitted on 2 Mar 2021

HAL is a multi-disciplinary open access archive for the deposit and dissemination of scientific research documents, whether they are published or not. The documents may come from teaching and research institutions in France or abroad, or from public or private research centers.
L'archive ouverte pluridisciplinaire HAL, est destinée au dépôt et à la diffusion de documents scientifiques de niveau recherche, publiés ou non, émanant des établissements d'enseignement et de recherche français ou étrangers, des laboratoires publics ou privés. 


\title{
NUMERICAL MODELING OF HYDROGEN COMBUSTION IN
} LARGE SCALE VOLUMES USING EUROPLEXUS CODE

\author{
Beccantini A. ${ }^{1}$,Velikorodny A. ${ }^{2}$,Studer E. ${ }^{3}$, Kudriakov S. ${ }^{4}$ \\ ${ }^{1}$ CEA/LATF, 91191, Gif-sur-Yvette, France, alberto.beccantini@cea.fr \\ ${ }^{2}$ AUSY, 92445, Issy-Les-Moulineaux, France, alexey.velikorodny@cea.fr, \\ ${ }^{3}$ CEA/LATF, 91191, Gif-sur-Yvette, France, etienne.studer@cea.fr, \\ ${ }^{4}$ CEA/LATF, 91191, Gif-sur-Yvette, France, skudriakov@cea.fr
}

\begin{abstract}
Numerical benchmarks on the subjects of combustion in large scale volumes and hydrogen safety, which were performed earlier have demonstrated, that current numerical algorithms and physical models experience poor predictive capabilities at the industrial scale, both due to under-resolution and simplifying approaches to combustion modeling. This article describes a validation of the EUROPLEXUS code against several large scale experimental data sets in order to improve its hydrogen combustion modeling capabilities in industrial settings (e.g. reactor buildings). The code employs an algorithm for the propagation of reactive interfaces, RDEM, which includes a combustion wave, as an integrable part of the Reactive Riemann problem, propagating with a fundamental flame speed (being a function of initial mixture properties as well as gas dynamics parameters). This approach makes unnecessary the application of a binary criterion function, which was used in order to determine flame position in "Forest-Fire"-type methods.
\end{abstract}

\section{Introduction}

Following the Three Miles Island accident understanding of necessity for hydrogen risk management had led to a great number of experimental programms in nuclear industry witn an aim to study the flame acceleration and the deflagration to detonation transition processes. The reference data on the large scale was obtained in the following facilities: RUT [Dorofeev et al., 1996], THAI [ISP-49], Battelle Model Containment (BMC) [Kanzleiter, 1997], and Heiss Dampf Reactor (HDR) [Wolf et al., 1999], among others. In addition, the medimum scale experiments were performed for example in ENACCEF [ISP-49] and DRIVER [Breitung et al., 2005] installations, where different regimes of flame propagation were identified. Some of these experiments were validated earlier the Cast3M code with the CREBCOM combustion model, [Kudriakov, 2006].

This paper presents the results of numerical simulations of hydrogen deflagrations using the RDEM combustion model [Beccantini et al., 2009], which was employed in the EUROPLEXUS code [EUROPLEXUS]. The model uses the parameter $K_{0}$ which represents a fundamental flame velocity, i.e. the flame velocity relative to the fresh mixture just ahead of it. The first model for this parameter was expressed as a product of several factors following [Bauwens et al., 2010]:

$$
K_{0}=S_{L}^{0} \Theta_{T H} \Theta_{T U R B} \Theta_{W R I N}
$$

where $S_{L}^{0}$ is the laminar flame speed of a gas mixture under consideration determined at reference temperature and pressure $\left(P_{0}, T_{0}\right), \Theta_{T H}$ is the thermodynamic factor which takes into account an influence of elevated pressure and temperature, $\Theta_{T U R B}$ is the turbulence factor, and $\Theta_{W R I N}$ is the flame wrinkling factor. Certain algebraic models and correlations 
are employed for each of these terms as it is described in [Studer et al., 2012]. Moreover, the user parameter $\Theta_{U}$ was introduced in the turbulence factor in order to validate the model. The methodology chosen for validation consists of a simple search of $\Theta_{U}$ parameter, which will minimize the error between the experimental and numerical flame speeds and/or overpressure curves.

A similar validation of the RDEM model has been already performed for the 17 tests in the RUT facility (on the large scale) both with hydrogen-air and hydrogen-air-vapor mixtures and described in [Studer et al., 2012]. It was demonstrated, in particular, that the $\Theta_{U}$ parameter of about 1.0 is sufficient to validate the model in the case without obstacles, while it varies between 2.0 and 4.0 in all other cases (with obstacles).

This paper, thus, contributes to a further validation of the RDEM model based on the data from BMC Ex29, HDR E12.3.2 and ENACCEF H13 experimental facilities, which permits to examine the capacities of the code in other complex geometries and to ameliorate a conservative law proposed in [Studer et al., 2012] for an a priori selection of the $\Theta_{U}$ parameter.

\section{Validation tests}

In this paper we consider three validation test cases: one test, ENACCEF H13, is the test where flame propagates during some time with velocity close to speed of sound in the burned gas, while the other two cases represent slow flame behaviour, i.e. maximum flame velocity is smaller than speed of sound in the fresh mixture.

The initial conditions are summarised in Table 1.

\begin{tabular}{|c|c|c|c|c|c|c|c|}
\hline Essai & $X_{\mathrm{H}_{2}}(\mathrm{vol} \%)$ & $X_{\mathrm{H}_{2} \mathrm{O}}$ & $X_{\mathrm{O}_{2}}$ & $X_{\mathrm{N}_{2}}$ & $T(\mathrm{~K})$ & $P$ (bar) & Commentaires \\
\hline \hline BMC Ex29 & 10.0 & 0.0 & 18.9 & 71.1 & 298.0 & 1.01325 & slow flame \\
\hline HDR E12.3.2 & 10.0 & 25.0 & 13.65 & 51.35 & 337.0 & 1.0 & slow flame \\
\hline ENACCEF H13 & 13.0 & 0.0 & 18.27 & 68.73 & 300.0 & 1.0 & fast flame \\
\hline
\end{tabular}

Table 1: Initial conditions and tests phenomenology.

\subsection{ENACCEF Test H13}

ENACCEF (ENceinte d'ACCElération de Flamme) is located at the Institut de Combustion Aérothermique Réactivité et Environnement (ICARE) of Orleans (CNRS).

View of ENACCEF facility together with the sketch of different parts are presented on Fig. 1. The facility is $5 \mathrm{~m}$ of height and is made of Z3CN18-10 stainless steel. It is divided into two parts:

- the acceleration tube (3.2 $\mathrm{m}$ long and $154 \mathrm{~mm}$ i.d.), in which repeated obstacles of various geometries can be inserted;

- the dome (1.7 $\mathrm{m}$ long, $738 \mathrm{~mm}$ i.d.).

The acceleration tube is equipped with two tungsten electrodes at $0.138 \mathrm{~m}$ from the bottom of the facility as a low-energy ignition device. The energy delivered is estimated to be around 10-20 mJ. Different obstacles of varying blockage ratio can be installed inside the tube. For the test, which we shall describe in the next subsection, nine annular obstacles of blockage ratio 0.63 have been installed in the acceleration tube; the first one being $0.638 \mathrm{~m}$ from the ignition point, and the distance between obstacles was fixed to $0.154 \mathrm{~m}$.

The ENACCEF Test $13 \mathrm{H}$ on hydrogen combustion has been dedicated to a homogeneous gas distribution in a containment volume, and is described in [ISP-49]. The initial gas composition, thermodynamic conditions, and fundamental parameters of the mixture are given in Table 2. 

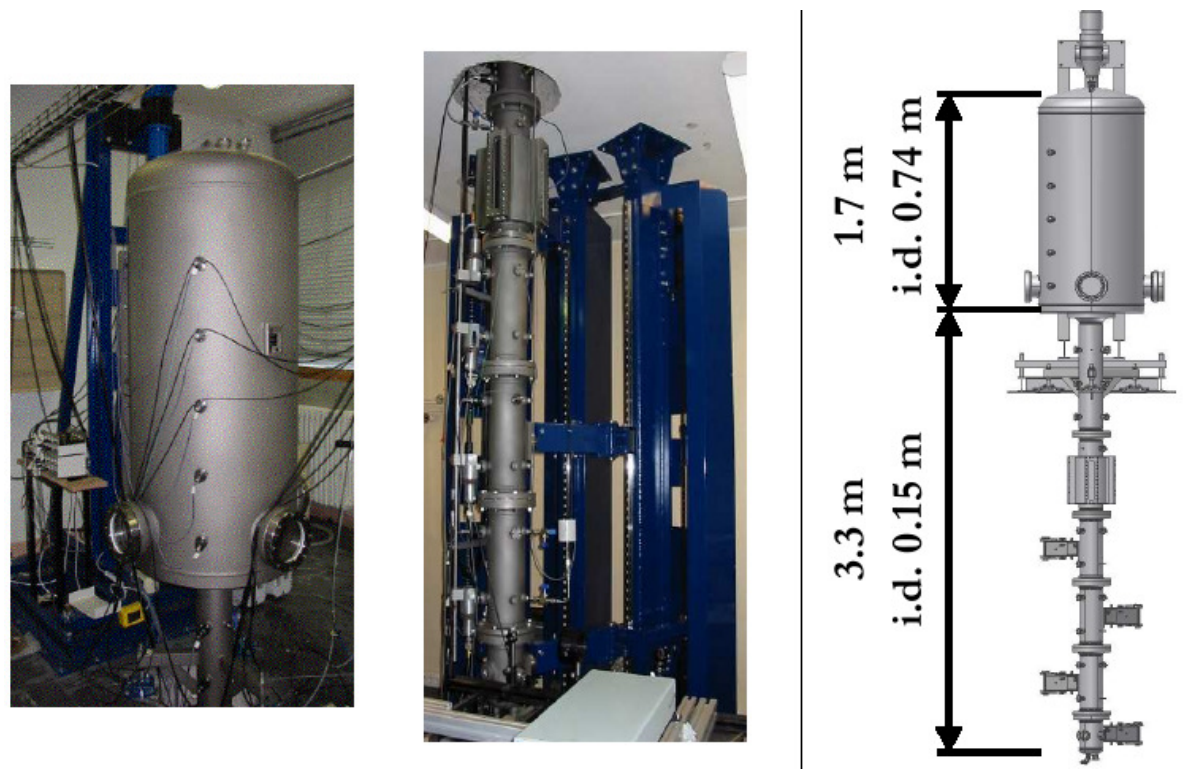

Figure 1: View of ENACCEF facility (left) and sketch of its different parts (right). Scanned from [ISP-49].

\begin{tabular}{|c|c|c|c|c|c|c|c|c|c|c|c|c|c|}
\hline Essai & {$\left[\mathrm{H}_{2} \mathrm{O}\right]$} & {$\left[\mathrm{H}_{2}\right]$} & {$\left[\mathrm{O}_{2}\right]$} & $\begin{array}{c}T \\
\mathrm{~K}\end{array}$ & $\begin{array}{c}P \\
\mathrm{bar}\end{array}$ & $\begin{array}{c}S_{L}^{0} \\
\mathrm{~m} / \mathrm{s}\end{array}$ & $\begin{array}{c}\delta_{l} \\
\mathrm{~mm}\end{array}$ & $\Phi$ & $\begin{array}{c}T_{A I B C} \\
\mathrm{~K}\end{array}$ & $L e_{E}$ & $L e_{D}$ & $L e_{e f f}$ & $\beta$ \\
\hline \hline $\mathrm{H} 13$ & 0.0 & 0.13 & 0.183 & 300.0 & 1.0 & 0.282 & 0.12 & 0.356 & 1320.8 & 1.525 & 0.376 & 0.490 & 4.445 \\
\hline
\end{tabular}

Table 2: Test ENACCEF H13 : mixture parameters used in 3D computations.

Experimental flame velocity is computed using the flame arrival times at the consecutive photomultipliers and the distance between them. Using the simple linear formula the flame velocities were computed for 24 runs. Flame velocities are given at the points which are mean positions between consecutive photomultipliers locations. We have computed the averaged flame velocities and presented them on the Fig. 2 together with the error bars showing flame velocity spread at each location. The averaged flame velocity at each location is based on the mean value of the sucessfully measured flame speeds.

Three phases of flame propagation inside the acceleration tube can be clearly distinguished:

- low flame velocity, equal to about $15-20 \mathrm{~m} / \mathrm{s}$ at the initial, non-obstructed part of the acceleration tube;

- strong flame acceleration up to $500-600 \mathrm{~m} / \mathrm{s}$ in the obstructed area;

- flame deceleration down to $300-400 \mathrm{~m} / \mathrm{s}$ in the upper non-obstructed part.

On the Fig. 3 we present the pressure evolution with time measured with Kistler transducer at the top of the dome (red line) The pressure is close to the initial value during initial 60 ms and then starts to rise upto AICC (Adiabatic Isochoric Complete Combustion) values. It should be noted that the volume ratio between the acceleration tube and the dome is $1: 12.2$. During the flame propagation along the acceleration tube only small fraction of hydrogen is burnt and some part of it is vented into the dome. Due to a large volume ratios this does not lead to a noticeable pressure increase in the dome. It is when the flame develops inside the dome, we observe the rapid pressure rise.

The computations have been performed in three dimensions and the numerical grid is presented on Fig. 4. For the coarse grid the tube radius is divided into 7 elements ( $R A F 1$, $\triangle x=1.15 \mathrm{~cm})$. This number is doubled for the second level of refinement $(R A F 2, \triangle x=5.73$ $\mathrm{mm})$. It should be noted, that a similar strategy was adopted for the large scale scenarios (see below), where from 3.5 to 14 elements were used on the characteristic radius, which 


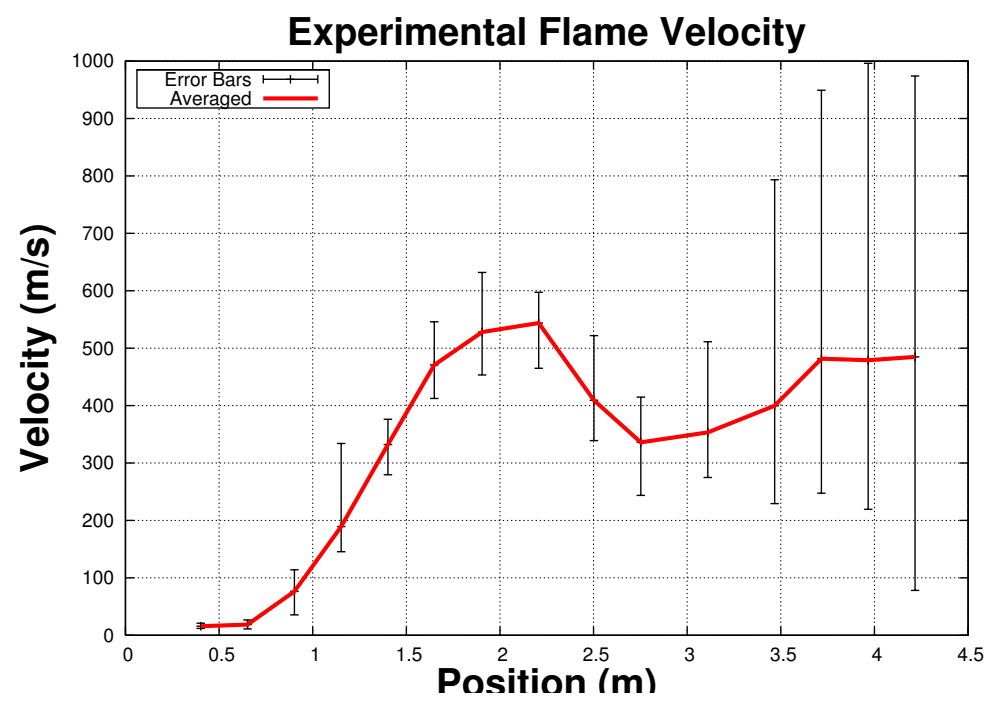

Figure 2: Averaged experimental flame velocities represented with maximum and minimum values.

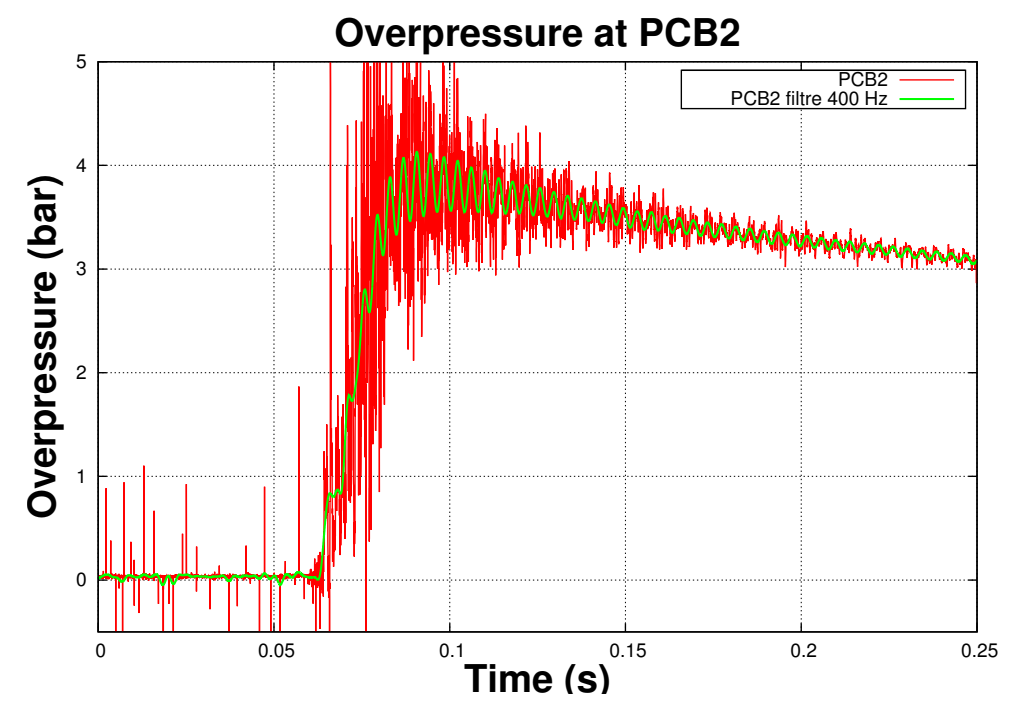

Figure 3: ENACCEF Test H13 : experimental overpressure. Raw signal (red curve) and filtered at $400 \mathrm{~Hz}$ signal (green curve). 
correspond to the mesh sizes from about 40 to $10 \mathrm{~cm}$, respectively. The model was largerly validated on the $20 \mathrm{~cm}$ mesh.

In the dome the elements are not uniform: their linear sizes gradually increase up to three times along the radius, and up to four times - along the axis of symmetry.

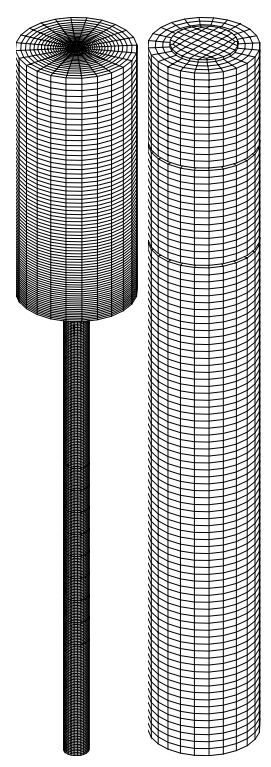

Figure 4: ENACCEF test H13 : the mesh $R A F 1$ (left) and a zoom on its lower part (right); $\triangle x=1.15 \mathrm{~cm}$.

The numerical solution for flame velocity obtained using $\Theta_{U}=3.89$ ( $R A F 1$ et $\left.R A F 2\right)$ is close to its experimental counterpart (Fig. 5). The computed flame velocity at the lower part of the facility $(z<1.2 \mathrm{~m})$ is higher than the experimental one because our combustion model does not take into account laminar flame developpment as well as transition from laminar to turbulent regime.

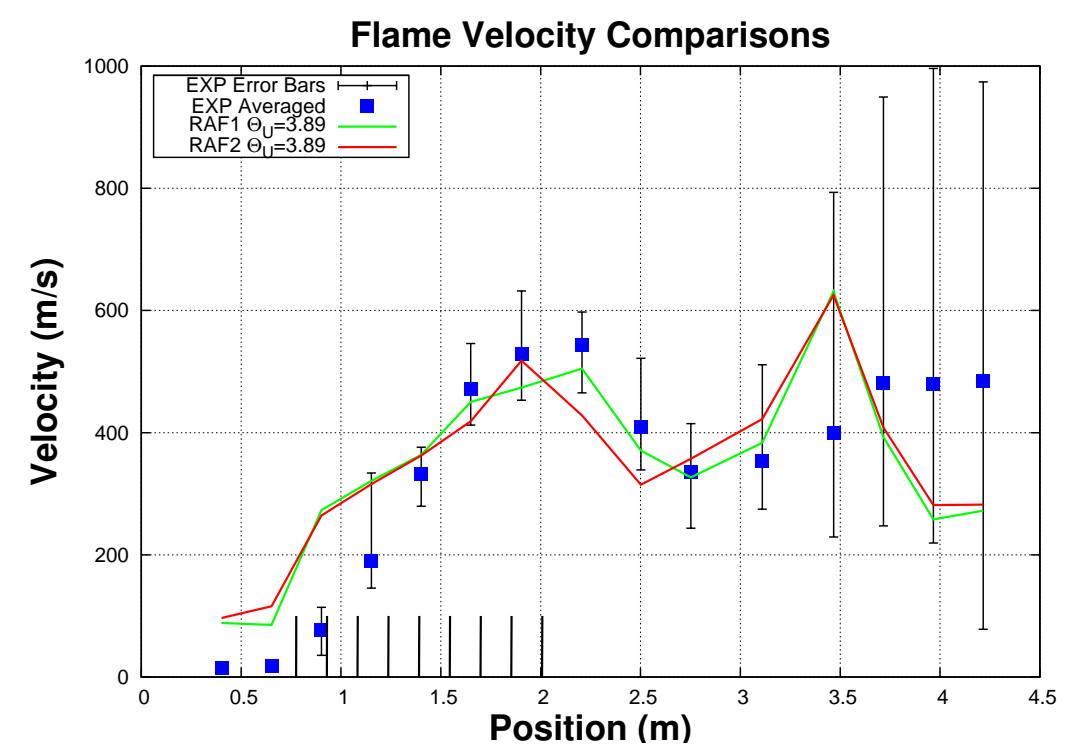

Figure 5: ENACCEF test H13 : comparison for flame velocity between experimental data and computed results.

The slope of the pressure rise corresponding to the computational results is very close to the slope of the experimental curve (Fig. 6). Moreover, the oscillatory behaviour of the numerical results is relatively well reproduced: the oscillation frequency $(\approx 250 \mathrm{~Hz})$ corresponds to one of the natural frequencies of the dome. 


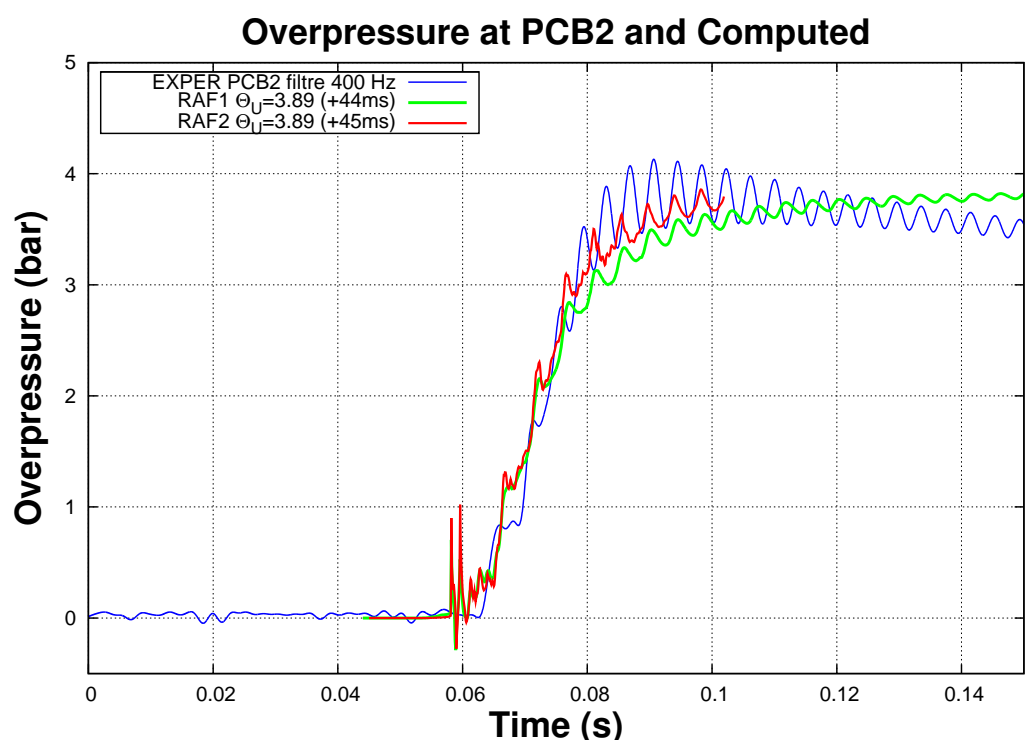

Figure 6: ENACCEF Test H13 : overpressure at the upper part of the dome. Comparison between experimental and numerical results.

\section{$2.2 \quad$ BMC test Ex29}

Several tests have been performed inside the Battelle Model Containement (BMC) $\left(640 \mathrm{~m}^{3}\right)$ using different arrangements for nine internal compartments (Fig. 7) ([Kanzleiter, 1997]). The BMC geometry used for the test Ex29 is presented in Figure 8. It consists of two

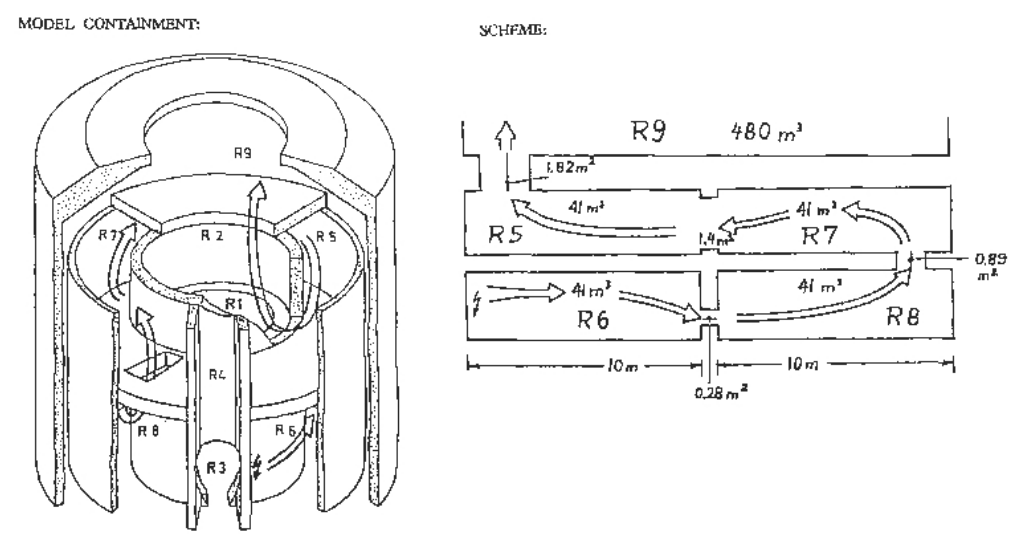

Figure 7: Battelle Model Containment tests : internal structures.

compartments $\mathbf{R} 7$ and $\mathbf{R 5}$ of the volume $41 \mathrm{~m}^{3}$ each separated by the vent of $1.4 \mathrm{~m}^{2}$ (blockage ratio $=66 \%$ ). In the room $\mathbf{R} 7$ there is an obstacle (cylinder) of the blockage ratio $50 \%$. At the farside of the room $\mathbf{R 5}$ there is a vent of the surface area $1.8 \mathrm{~m}^{2}$. This vent leads to the dome of the containment $\left(480 \mathrm{~m}^{3}\right)$.

The initial gas composition, thermodynamic conditions, and fundamental parameters of the mixture are given in Table 3 .

Iginition takes place at the farside of the room R7. During the experiments it was found that the flame accelerates after it passes the cylindrical obstacle. The highest peak pressure of 1.9 bar is reached soon after the flame enters the room R5 (see Figure 9).

The numerical meshes used for computations are: coarse mesh with $\triangle x=41.6 \mathrm{~cm}$ (RAF1), medium mesh with $\triangle x=20.8 \mathrm{~cm}$ (RAF2), and fine mesh with $\triangle x=10.4 \mathrm{~cm}$ (RAF4). The mesh $R A F 4$ of two compartments $R 5$ et $R 7$ together with total mesh, which includes the compartment $R 9$, are shown on Figure 10. 


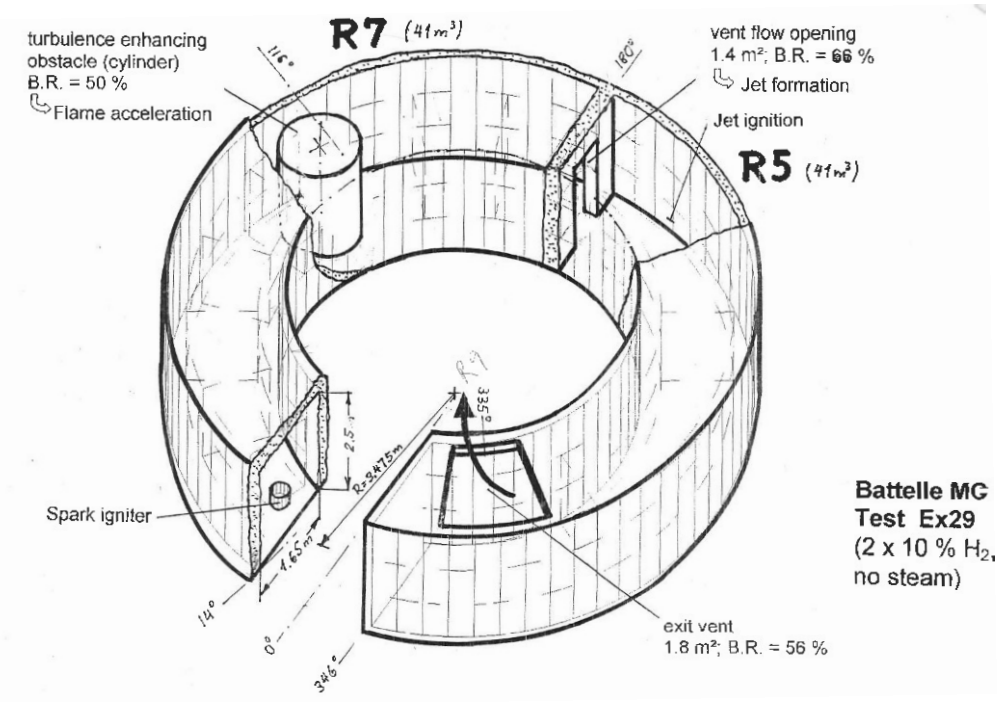

Figure 8: Expérience Battelle Model Containment : arrangement for Test Ex29.

\begin{tabular}{|c|c|c|c|c|c|c|c|c|c|c|c|c|c|}
\hline Essai & {$\left[\mathrm{H}_{2} \mathrm{O}\right]$} & {$\left[\mathrm{H}_{2}\right]$} & {$\left[\mathrm{O}_{2}\right]$} & $\begin{array}{c}T \\
\mathrm{~K}\end{array}$ & $\begin{array}{c}P \\
\mathrm{bar}\end{array}$ & $\begin{array}{c}S_{L}^{0} \\
\mathrm{~m} / \mathrm{s}\end{array}$ & $\begin{array}{c}\delta_{l} \\
\mathrm{~mm}\end{array}$ & $\Phi$ & $\begin{array}{c}T_{A I B C} \\
\mathrm{~K}\end{array}$ & $L e_{E}$ & $L e_{D}$ & $L e_{e f f}$ & $\beta$ \\
\hline \hline Ex29 & 0.0 & 0.1 & 0.189 & 298.0 & 1.013 & 0.157 & 0.2 & 0.265 & 1091.7 & 1.456 & 0.362 & 0.429 & 5.081 \\
\hline
\end{tabular}

Table 3: BMC test Ex29 : mixture parameters used in 3D computations.

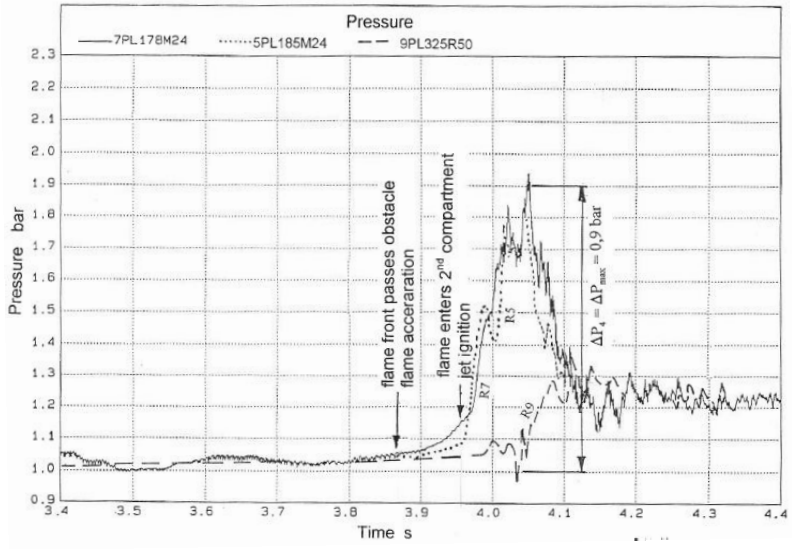

Figure 9: BMC test Ex29 : experimental pressure [Kanzleiter, 1997].

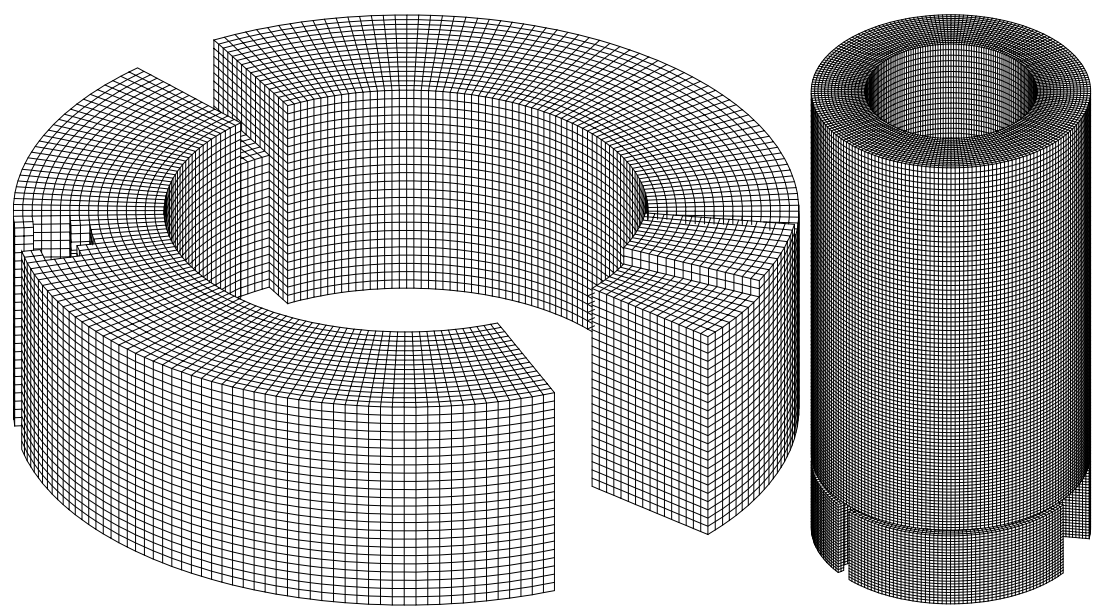

Figure 10: BMC test Ex29 : the mesh $R A F 4$ of $R 5$ and $R 7$ (left), and total mesh $R A F 4$ (right), $\triangle x=10.4$ $\mathrm{cm}$. 
Validation has been performed based on the experimental data for pressure, as we do not have experimental results for flame velocity. The numerical solutions using values for user parameter $\Theta_{U}=4.44(R A F 1)$ and $\Theta_{U}=3.33$ ( $R A F 2$ and $R A F 4$ ) well reproduce the experimental pressure evolution (Fig. 11). We can thus conclude that the user parameter $\Theta_{U}$ decreases when the flame surface area is better reproduced on the finer meshes (RAF2 and RAF4). The computed curves for pressure variable are shifted in time $(\Delta t=3.7 \mathrm{~s})$ for comparison. This time period corresponds to flame arrival at the door between the compartments $R^{r}$ and $R 5$. Flame velocity along the curviliner distance of the containment is presented in Figure 12. We can see that the maximum flame velocity is achieved when the flow experiences contraction at the door level, and this maximum is below or close to the speed of sound in fresh mixture.

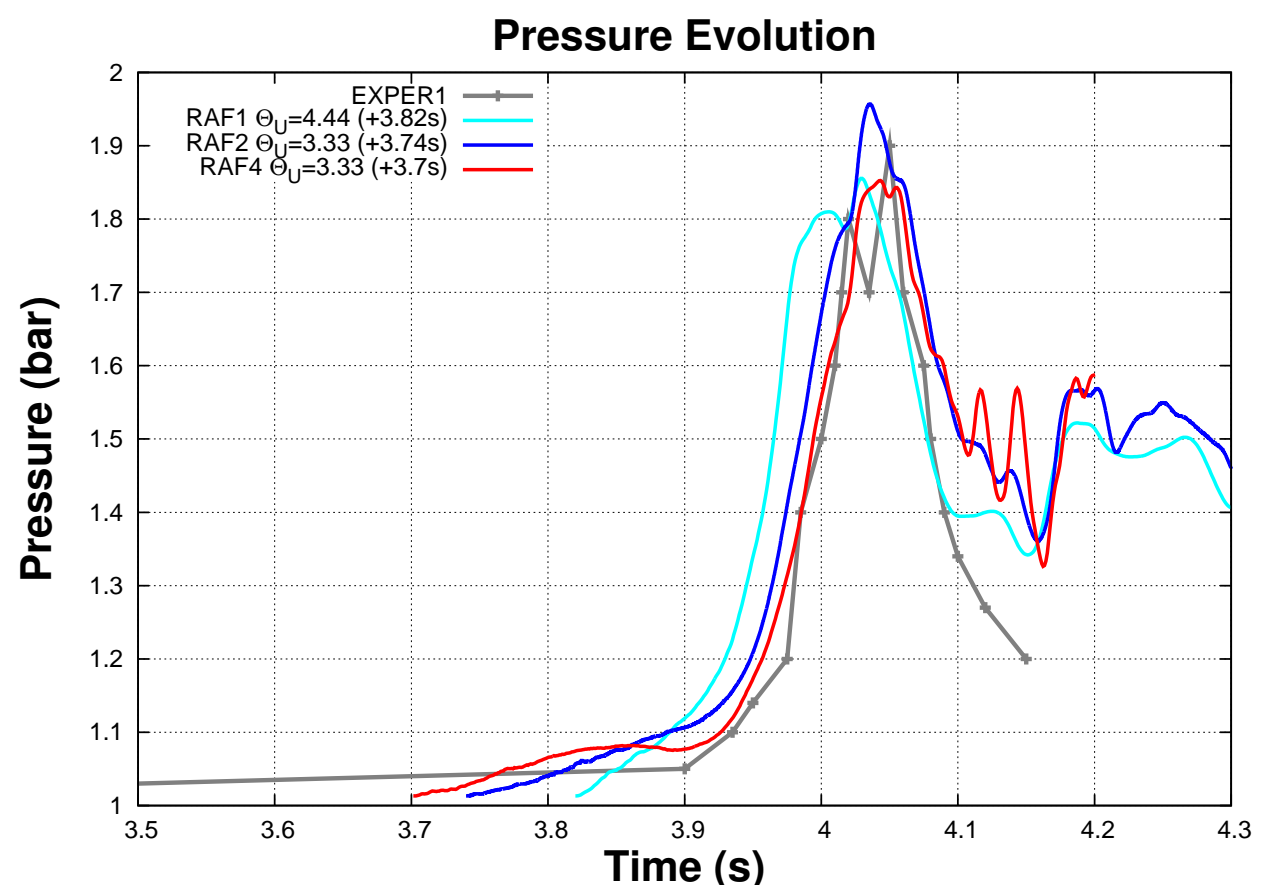

Figure 11: BMC test Ex29: comparison between computed and experimental results for pressure.

\subsection{HDR test E12.3.2}

The set of subcompartments chosen for test E12.3.2 [Wolf et al., 1999], consists of the chain of interconnected subcompartments R1.904, R1.905 and R1.801 of total volume of $530 \mathrm{~m}^{3}$, as shown in Figure 13 (left). Figure 13 (right) depicts the top view of the arrangement of the three subcompartments showing the asymmetrically positioned vent between R1.904 and $\mathrm{R} 1.801$. The surface is $2.34 \mathrm{~m}^{2}$ between $\mathrm{R} 1.905$ et $\mathrm{R} 1.801$, and is $4.68 \mathrm{~m}^{2}$ between $\mathrm{R} 1.801$ and the dome.

The initial gas composition, thermodynamic conditions, and fundamental parameters of the mixture are given in Table 4 . The mixture is ignited at the left end of the compartment R1.904 (see Fig. 13, left).

\begin{tabular}{|c|c|c|c|c|c|c|c|c|c|c|c|c|c|}
\hline Essai & {$\left[\mathrm{H}_{2} \mathrm{O}\right]$} & {$\left[\mathrm{H}_{2}\right]$} & {$\left[\mathrm{O}_{2}\right]$} & $\begin{array}{c}T \\
\mathrm{~K}\end{array}$ & $\begin{array}{c}P \\
\mathrm{bar}\end{array}$ & $\begin{array}{c}S_{L}^{0} \\
\mathrm{~m} / \mathrm{s}\end{array}$ & $\begin{array}{c}\delta_{l} \\
\mathrm{~mm}\end{array}$ & $\Phi$ & $\begin{array}{c}T_{A I B C} \\
\mathrm{~K}\end{array}$ & $L e_{E}$ & $L e_{D}$ & $L e_{\text {eff }}$ & $\beta$ \\
\hline \hline E12.3.2 & 0.25 & 0.1 & 0.137 & 337.0 & 1.0 & 0.12 & 0.29 & 0.366 & 1087.8 & 1.198 & 0.304 & 0.391 & 4.818 \\
\hline
\end{tabular}

Table 4: HDR test E12.3.2 : mixture parameters used in 3D computations.

During the experiments it was found that the accelerated jet ignition results in the highest 


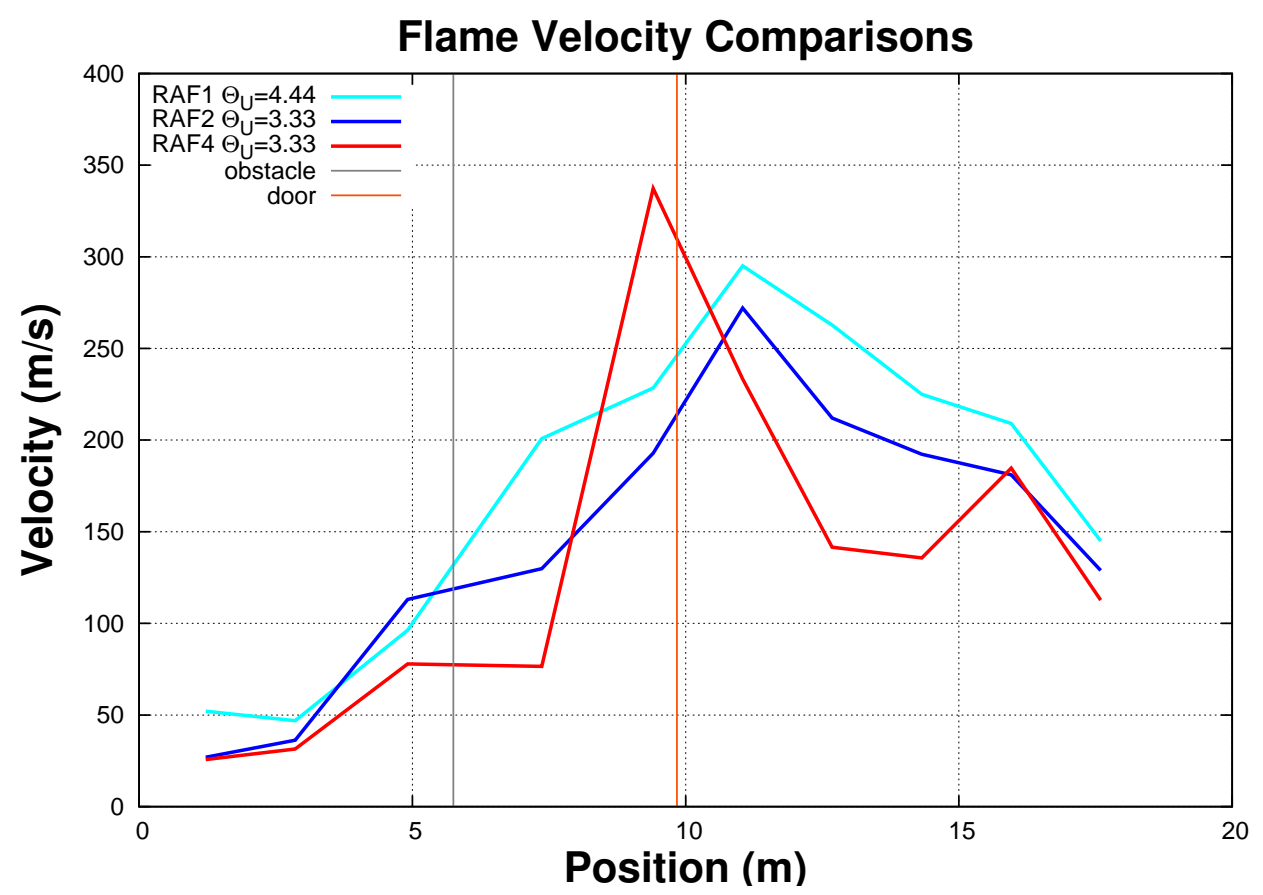

Figure 12: BMC test Ex29: computed flame velocity for different grids.
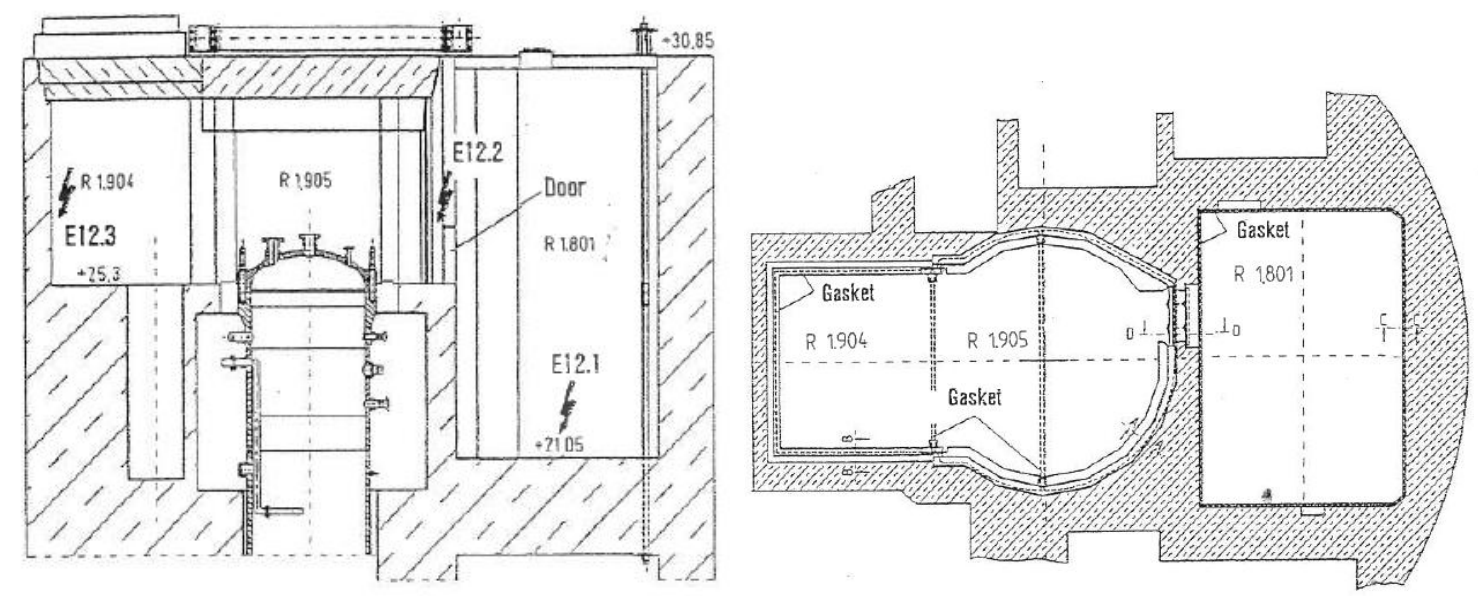

Figure 13: HDR test E12.3.2 : lateral view (left) and top view (right) 
peak pressure of 1.3 bar (see Figure 14). Averaged experimental flame velocity is quite small,

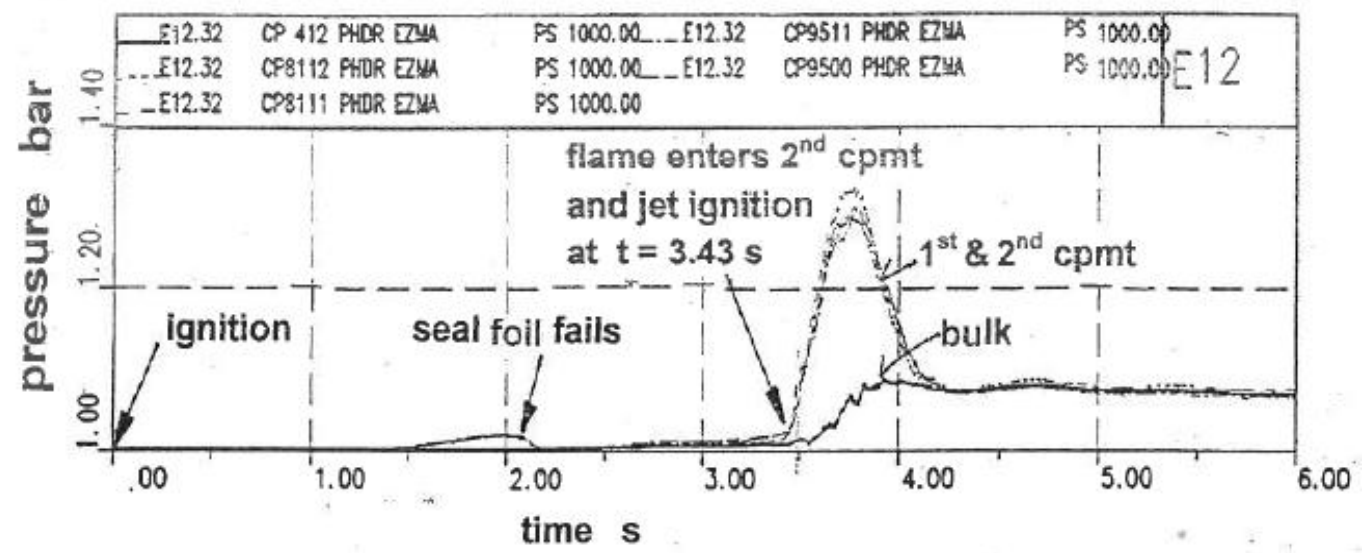

Figure 14: HDR test E12.3.2 : experimental pressure [Wolf et al., 1999].

of the order of $2.8 \mathrm{~m} / \mathrm{s}$.

The numerical meshes used for computations are: coarse mesh with $\triangle x=38.4 \mathrm{~cm}(R A F 1)$, fine mesh with $\triangle x=18.6 \mathrm{~cm}(R A F 2)$. The fine mesh of the three compartments, R1.904, $\mathrm{R} 1.905$ et R1.801, and the total mesh with the dome (R1.1004) (volume $5000 \mathrm{~m}^{3}$ ) are presented on Figure 15.

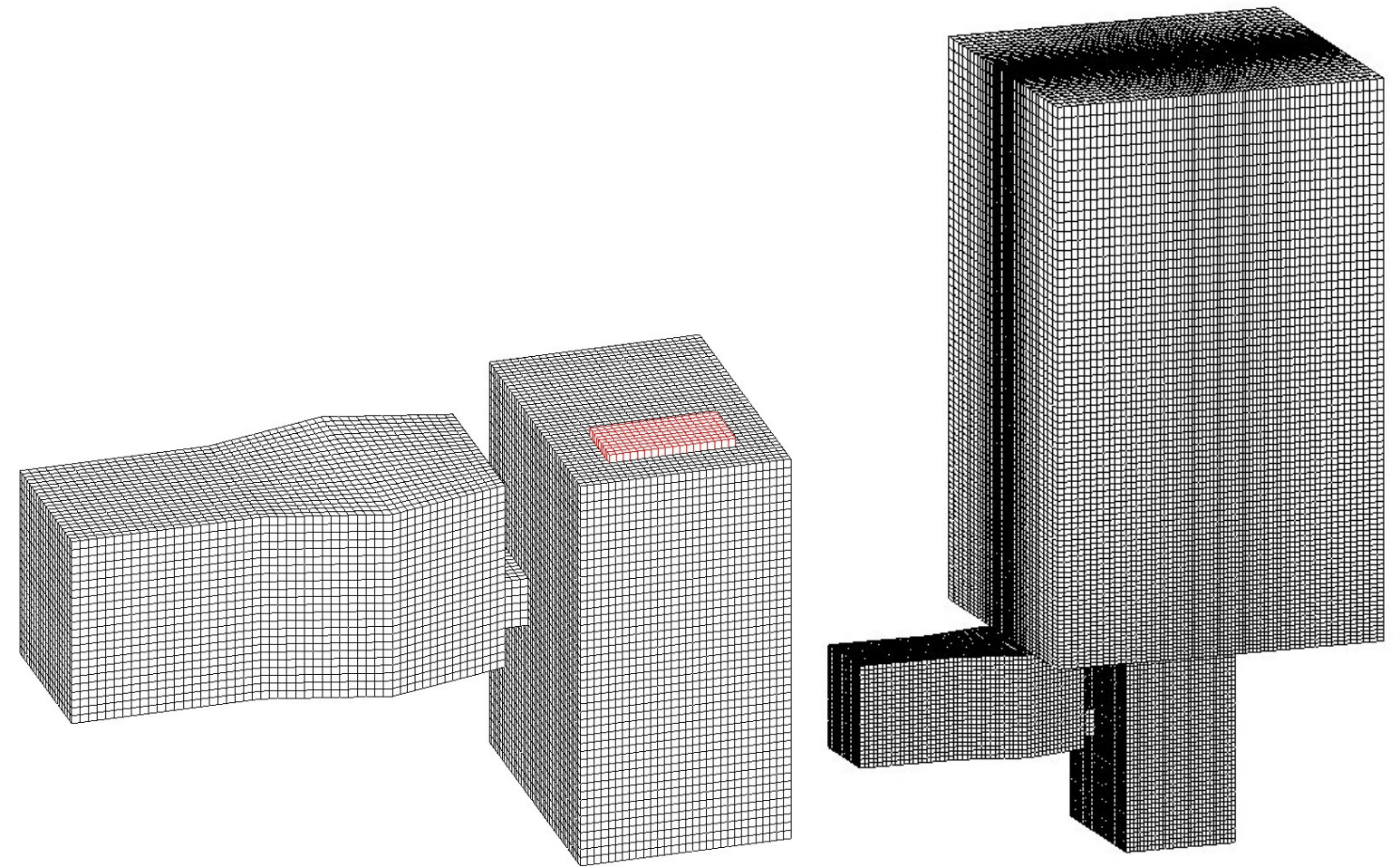

Figure 15: HDR test E12.3.2: mesh RAF2 of R1.904, R1.905 and R1.801 (left) and the total mesh RAF2 (right), $\triangle x=10.4 \mathrm{~cm}$.

Validation has been performed based on the experimental data for pressure, as we do not have experimental results for flame velocity. The numerical solutions using values for user parameter $\Theta_{U}=1.0(R A F 1)$ and $\Theta_{U}=0.69(R A F 2)$ well reproduce the experimental pressure evolution (Fig. 16). The computed curves for pressure variable are shifted in time $(\triangle t=2.6-2.8 \mathrm{~s})$ for comparison. This time period corresponds to flame arrival at the 
door between the compartments R1.905 et R1.801. Flame velocity along the compartments is presented in Figure 17. We can see that this velocity is much smaller than the speed of sound in fresh mixture.

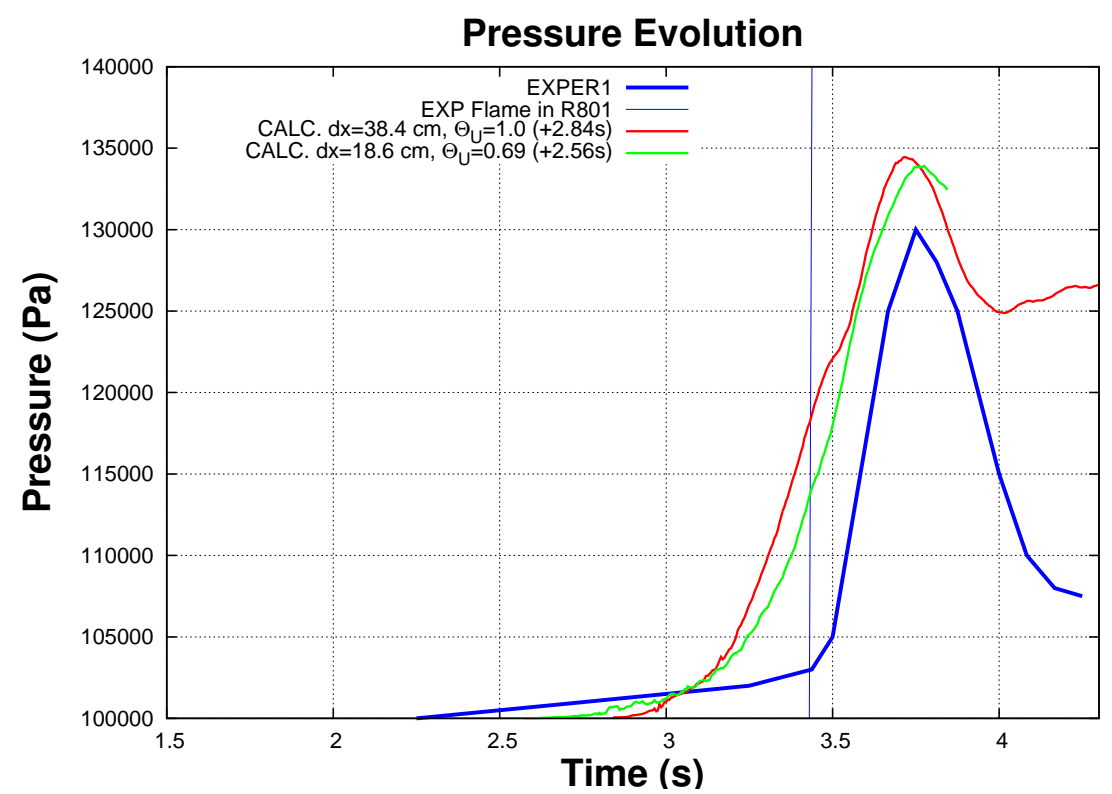

Figure 16: HDR test E12.3.2 : comparison between experimental and computed results for pressure.

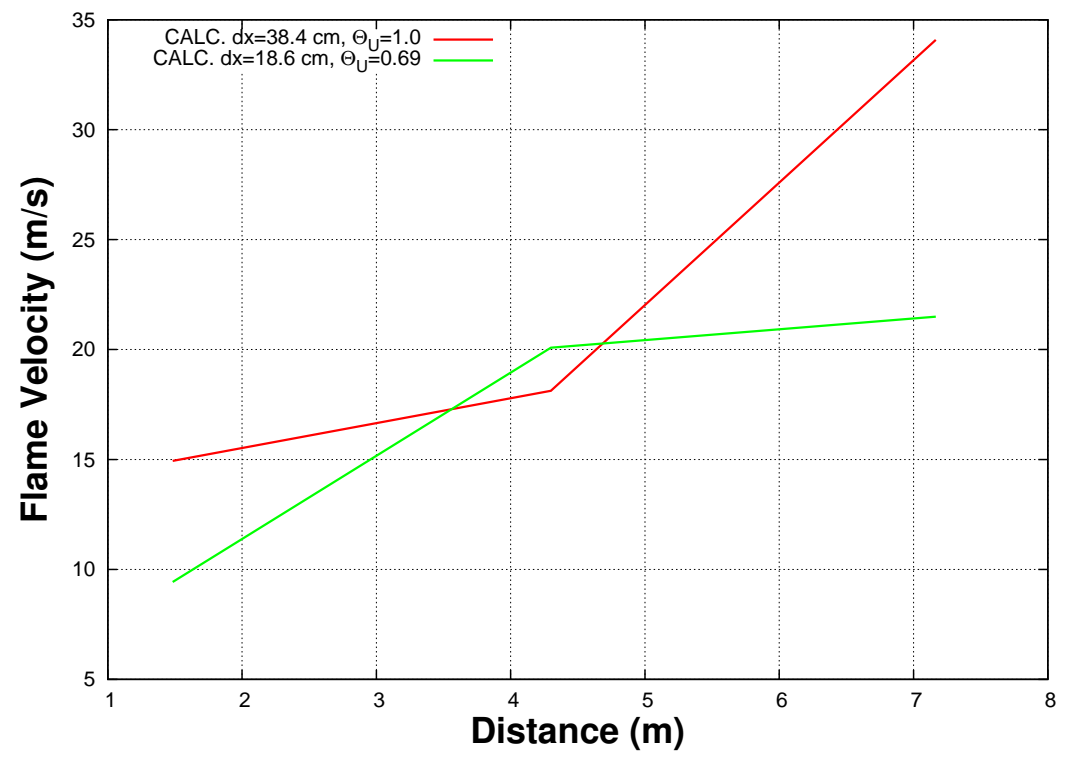

Figure 17: HDR test E12.3.2 : computed flame velocity 


\section{Conclusions}

This paper reports a validation of the combustion model implemented in the EUROPLEXUS code based on the data obtained in BMC, HDR and ENACCEF experimental facilities. The model shows a rather good behaviour in terms of flame speeds and overpressure curves ones the values of the $\Theta_{U}$ parameter are correctly chosen. These are summarized together with other important initial parameters, including the mesh size, for considered tests in Table 5 .

\begin{tabular}{|c|c|c|c|c|c|c|c|c|c|c|c|}
\hline Test & {$\left[\mathrm{H}_{2} \mathrm{O}\right]$} & {$\left[\mathrm{H}_{2}\right]$} & {$\left[\mathrm{O}_{2}\right]$} & $\begin{array}{c}\mathrm{T} \\
\mathrm{K}\end{array}$ & $\begin{array}{c}P \\
\mathrm{bar}\end{array}$ & $\begin{array}{c}S_{L}^{0} \\
\mathrm{~m} / \mathrm{s}\end{array}$ & $\begin{array}{c}\delta_{l} \\
\mathrm{~mm}\end{array}$ & $\begin{array}{c}\text { Leff } \\
\text { eff }\end{array}$ & $\Theta_{U}$ & $\begin{array}{c}\triangle x_{\text {ref }} \\
\mathrm{m}\end{array}$ & $\begin{array}{c}\triangle x_{\text {autres }} \\
\mathrm{m}\end{array}$ \\
\hline \hline BMC & 0.0 & 0.1 & 0.189 & 298.0 & 1.013 & 0.157 & 0.2 & 0.429 & $\mathbf{3 . 3}$ & 0.208 & $0.416 ; 0.104$ \\
\hline HDR & 0.25 & 0.1 & 0.137 & 337.0 & 1.0 & 0.12 & 0.29 & 0.391 & $\mathbf{0 . 7}$ & 0.189 & 0.384 \\
\hline ENACCEF & 0.0 & 0.13 & 0.183 & 300.0 & 1.0 & 0.282 & 0.12 & 0.490 & $\mathbf{3 . 8 9}$ & $5.73 \mathrm{D}-3$ & $1.15 \mathrm{D}-2$ \\
\hline
\end{tabular}

Table 5: Main parameters of the model.

The main conclusions on the choice of the $\Theta_{U}$ parameter are as follows:

- for all tests considered the values of $\Theta_{U}$ are less than 4.0;

- for the case with a single obstacle (HDR), one has to choose the $\Theta_{U}$ of the order of 1.0, which is similar to the case without obstacles;

- for tests with a series of obstacles the parameter varies between 3.0 and 4.0.

These results together with the ones obtained for the RUT facility permited to derive a conservative law, which provides an analytical curve for the a priori determination of the $\Theta_{U}$ parameter, as a function of laminar flame characteristics (e.g. $S_{L}^{0}$, etc).

The sensitive point of the model is that the initial acceleration of the flame is much greater when compared to the experiments. However, it should be noted, that experimentaly this initial phase of the flame development is also difficult to reproduce. For example, the ENACCEF H13 test was performed 24 times with the virtually same initial conditions and the resulting flame speed on the level of the first transducer varied significantly.

In order to perfom a rigorous validation of combustion models on the large scale one needs to obtain experimentaly not only the visible flame speed and pressure curves, but also a growth of the flame surface area and the gaz velocity field. 


\section{References}

[Beccantini et al., 2009] Beccantini A. and Studer E. The reactive Riemann problem for thermally perfect gases at all combustion regimes. International Journal for Numerical Methods in Fluids. 2009.

[Bauwens et al., 2010] Bauwens, C. R., Chaffee, J., and Dorofeev, S. (2010). Vented explosion overpressures from combustion of hydrogen and hydrocarbon mixtures. International Journal of Hydrogen Energy, 36(3):2329-2336.

[Dellacherie, 2010] Analysis of Godunov type schemes applied to the compressible Euler system at low Mach number, Journal of Computational Physics 229, 978-1016, 2010.

[Breitung et al., 2005] Breitung, W., S. Dorofeev, A. Kotchourko, R. Redlinger, W. Scholtyssek, A. Bentaib, J.-P. L'Heriteau, P. Pailhories, J. Eyink, M. Movahed, K.-G. Petzold, M. Heitsch, V. Alekseev, A. Denkevits, M. Kuznetsov, A. Efimenko, M.V. Okun, T. Huld, D. Baraldi (2005). Integral large scale experiments on hydrogen combustion for severe accident code validation-HYCOM. Nuclear Engineering and Design, 235(2-4):253270.

[Dorofeev et al., 1996] Dorofeev, S. B., Sidorov, V. P., Dvoinishnikov, A. E., and Breitung, W. (1996). Deflagration to detonation transition in large confined volume of lean hydrogenair mixtures. Combustion and flame, 104:95-110.

[EUROPLEXUS] http://europlexus.jrc.ec.europa.eu/

[ISP-49] ISP-49 on Hydrogen Combustion, Nuclear Safety, NEA/CSNI/R(2011)9, 2012.

[Kanzleiter, 1997] T. Kanzleiter, BMC and DN400 Hydrogen Deflagration Tests. Proposal for a test matrix with a link to MUSCET and HDR Tests, Third Meeting of the Group of Experts on the Development of a Phenomena-based Validation Matrix for Ex-vessel Models and Codes, January 15-16, GRS, Garching, Germany, 2004.

[Kudriakov, 2006] S. Kudriakov, A. Beccantini, F. Dabbene, H. Paillere, E. Studer, Evaluation of different H2-Air combustion models for the simulation of large scale confined deflagrations. Journal of the Energy Institute, Vol79(4), 200-206, (2006).

[ISP49, 2012] ISP49(2012). ISP-49 on hydrogen combustion. Technical report, NEA/CSNI/R(2011)9.

[Malet, 2004] Malet, F. (2004). Etude expérimentale et numérique de la propagation de flammes prémélangées turbulentes dans une atmosphère pauvre en hydrogène et humide. PhD thesis, Université d'Orléans.

[Studer et al., 2012] E. Studer, A. Beccantini, S. Kudriakov, and A. Velikorodny (2013) Hydrogen combustion modelling in large scale geometries. International Conference On $\mathrm{Nu}$ clear Engineering, July 29 - August 2, 2013, Chengdu, China.

[Wolf et al., 1999] L. Wolf and A. Rastogi, Detailed assesment of the Heiss Dampf Reactor hydrogen deflagration experiments E12. Nuclear Technology, 125, 1999. 